\title{
Staged treatment of mega aortic syndrome using the frozen elephant trunk and hybrid thoracoabdominal repair
}

\author{
Asimakis Gkremoutis, MD, ${ }^{\mathrm{a}}$ Andreas Zierer, MD, ${ }^{\mathrm{b}}$ Thomas Schmitz-Rixen, MD, ${ }^{\mathrm{a}}$ \\ Ali El-Sayed Ahmad, MD, ${ }^{\mathrm{c}}$ Erhard Kaiser, MD, ${ }^{\mathrm{e}}$ Michael Keese, MD, ${ }^{\mathrm{a}}$ and Thomas Schmandra, MD $^{\mathrm{d}}$
}

\section{ABSTRACT}

Objective: We report our experience with a staged hybrid approach for the treatment of extended aortic disease, also known as "mega aortic syndrome."

Methods: A total of 15 patients (10 male, 5 female) underwent staged repair of the thoracoabdominal aorta, consisting of 3 separate stages (repair of ascending aorta and aortic arch using the frozen elephant trunk technique and hybrid thoracoabdominal repair with debranching of the renovisceral branches and stent graft implantation).

Results: The procedure was completed in 14 patients. After the first stage (repair of ascending aorta and aortic arch), no mortality or spinal cord ischemia occurred. One patient required temporary dialysis. After the thoracoabdominal repair, permanent paraplegia developed in 1 patient. One patient died intraoperatively after aneurysm rupture. The in-hospital mortality for the complete repair reached $6.7 \%$. None of the surviving patients required permanent dialysis. Interval aortic events consisted of 1 contained rupture.

Conclusions: The concept of a staged hybrid repair of the mega aortic syndrome is technically feasible. The frozen elephant trunk technique represents an attractive treatment option, offering an adequate landing zone for later thoracoabdominal repair in patients with extended aortic disease. For completion of the repair, a staged hybrid approach with renovisceral debranching and aneurysm exclusion using off-the-shelf stent grafts shows promising results with low surgical morbidity and mortality. (J Thorac Cardiovasc Surg 2017;154:1842-9)

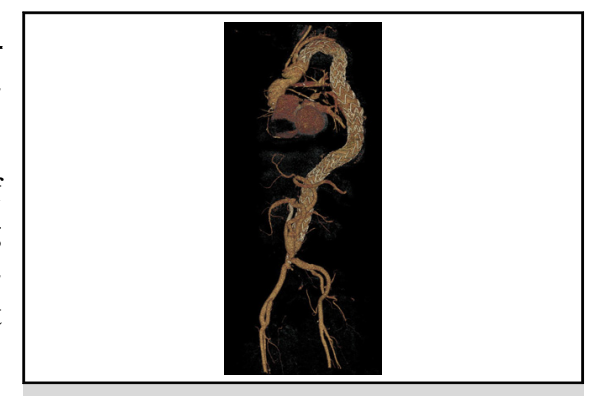

Postoperative computed tomography scan with 3dimensional reconstruction after completion of the hybrid procedure, depicting patent bypass grafts after debranching and complete exclusion of the aneurys matic aorta.

\section{Central Message}

A multistaged approach (FET and hybrid thoracoabdominal repair) in the treatment of extensive aortic disease is technically feasible and shows promising results with acceptable mortality and morbidity.

\section{Perspective}

Mega aortic syndrome is a challenging clinical entity for both the patient and the surgical team. Data regarding treatment options for such pathologies are limited. We present our concept of a multistaged approach using both open and endovascular techniques for the different operation stages, describing an alternative treatment option with promising results for this challenging pathology.

See Editorial Commentary page 1850 .

\footnotetext{
From the Departments of ${ }^{\mathrm{a}}$ Vascular and Endovascular Surgery, ${ }^{\mathrm{c}}$ Thoracic and Cardiovascular Surgery, University Hospital Frankfurt; ${ }^{\mathrm{e} P r i v a t e}$ Clinic for Cardiology, Frankfurt am Main; 'bepartment of Cardiac and Thoracic Surgery, Helios Klinikum Siegburg, Siegburg; ${ }^{\mathrm{d}}$ Department of Vascular Surgery, Rhön Klinikum, Bad Neustadt, Germany.

Received for publication Dec 18, 2016; revisions received June 11, 2017; accepted for publication June 19, 2017; available ahead of print July 19, 2017.

Address for reprints: Asimakis Gkremoutis, MD, Department of Vascular and Endovascular Surgery, University Hospital Frankfurt, Theodor-Stern-Kai 7, Frankfurt am Main 60590, Germany (E-mail: asimakis.gkremoutis@kgu.de).

$0022-5223 / \$ 36.00$

Copyright (c) 2017 by The American Association for Thoracic Surgery

http://dx.doi.org/10.1016/j.jtcvs.2017.06.038
}

The aneurysmatic dilatation of the whole aorta, involving the ascending aorta, the aortic arch, and the descending and abdominal aorta, may it be of degenerative origin or a

Scanning this $\mathrm{QR}$ code will take you to a supplemental video for the article. 


\section{Abbreviation and Acronym \\ $\mathrm{FET}=$ frozen elephant trunk}

consequence of aortic dissection and also known as "mega aortic syndrome," is a relatively rare entity and requires extensive repair procedures. Open surgical treatment is currently the standard treatment, and although adjunctive measures have reduced mortality and morbidity, both remain significant. Endovascular techniques for treating extended aortic aneurysms are rapidly evolving; a total endovascular approach in this case is nevertheless still not feasible, given the lack of specific devices to treat all vital branches, as well as individual anatomic limitations and various configurations of the aneurysmatic aorta. Hybrid procedures have been introduced to minimize surgical trauma by creating adequate landing zones for endovascular repair using offthe-shelf stent grafts. ${ }^{1}$ Furthermore, studies have indicated that staging the aortic repair attenuates surgical trauma and seems to reduce morbidity, ${ }^{2,3}$ although aneurysmrelated interval mortality ${ }^{3}$ and patient compliance to undergo the latter stages ${ }^{4}$ remain important issues. Our concept consists of open repair of the ascending aorta and the aortic arch using the frozen elephant trunk (FET) technique ${ }^{5}$ and completion with a staged hybrid repair of the thoracoabdominal aorta. ${ }^{6}$ We present our patient cohort to assess the outcome in terms of technique feasibility and safety.

\section{PATIENTS AND METHODS}

\section{Data Collection}

Patients were included in a registry with prospective collected data. After completion of the procedure, frequent follow-up was performed at 1, 3, 6, and 12 months by means of clinical examination, ultrasound, and computed tomography scans. Annual follow-up was performed thereafter. Approval from the ethics committee was obtained, and patients signed a written informed consent preoperatively.

\section{Surgical Technique}

The open repair of the ascending aorta and the aortic arch is performed through a median sternotomy (partial or total) using circulatory arrest. The procedure is carried out under mild hypothermia with selective antegrade cerebral perfusion. Arterial and venous cannulation is preferably achieved via the right subclavian artery and the right atrium, respectively, and cardiopulmonary bypass is established. The patient is cooled and the aorta is crossclamped. Antegrade or retrograde blood cardioplegia is applied. The patient is placed in the Trendelenburg position, the aorta is then transected, and brain perfusion is initiated. Backflow is controlled after inserting Fogarty catheters or clamping. In selected patients, cannulation of the left carotid artery also can be performed. Transection of the aortic arch is continued, and the supra-aortic vessels are dissected as an island patch. The stented part of a hybrid graft is then deployed in the descending aorta over a stiff guidewire, which is introduced in an antegrade fashion or using a through-and-through technique via the common femoral artery. The hybrid graft is then anastomosed to the proximal descending aorta using a pledgeted continuous, nonabsorbable suture. The proximal part of the hybrid graft ("not stented") is then unfolded, and after excision of a corresponding segment on the cranial surface, a patch anastomosis with the arch vessels is carried out, using a plegdeted continuous, nonabsorbable suture. The reconstruction is de-aired, the graft is clamped proximally, and perfusion is reestablished. The proximal anastomosis with the native ascending aorta or preexisting grafts is completed while the patient is being warmed (Figure 1). After de-airing, the aortic clamp is removed and additional adjunct procedures are carried out if necessary (ie, aortocoronary bypass or valve reconstruction). Decannulation is then performed, and the procedure is completed (Figure 2).

We have previously described the hybrid procedure for thoracoabdominal repair. ${ }^{6}$ Through a median laparotomy and a transabdominal approach, the abdominal aorta and the origins of the celiac trunk, the superior mesenteric, and the renal arteries are exposed. In cases with extended aneurysmatic dilation reaching the aortic bifurcation or even further, an infrarenal repair with a tube or bifurcated graft is carried out to provide an adequate landing zone and facilitate debranching. Grafts originating from the infrarenal aorta, the iliac arteries, or the aortic graft are then anastomosed to the renovisceral arteries (Video 1). Alternatively, hybrid grafts are used to avoid complete dissection of the target vessels and reduce anastomosis and thus ischemia time. The origins of the renovisceral vessels are then ligated, and the operation is completed (Figure 3).

Stent grafts are introduced during a third stage via the common femoral artery, which is surgically dissected or over an iliac conduit after retroperitoneal exposure to achieve exclusion of the aneurysm (Figure 4). A throughand-through guidewire technique is sometimes used to facilitate stent graft deployment and reduce procedure-related complications. Radiopaque markers placed intraoperatively allow for optimal identification of the distal landing zone. A spinal drainage is placed to monitor spinal fluid pressure.

\section{RESULTS}

\section{Demographic Data and Comorbidity}

From 2007 to 2016, 15 patients were identified, of whom $10(66.7 \%)$ were male and $5(33.3 \%)$ were female. Six

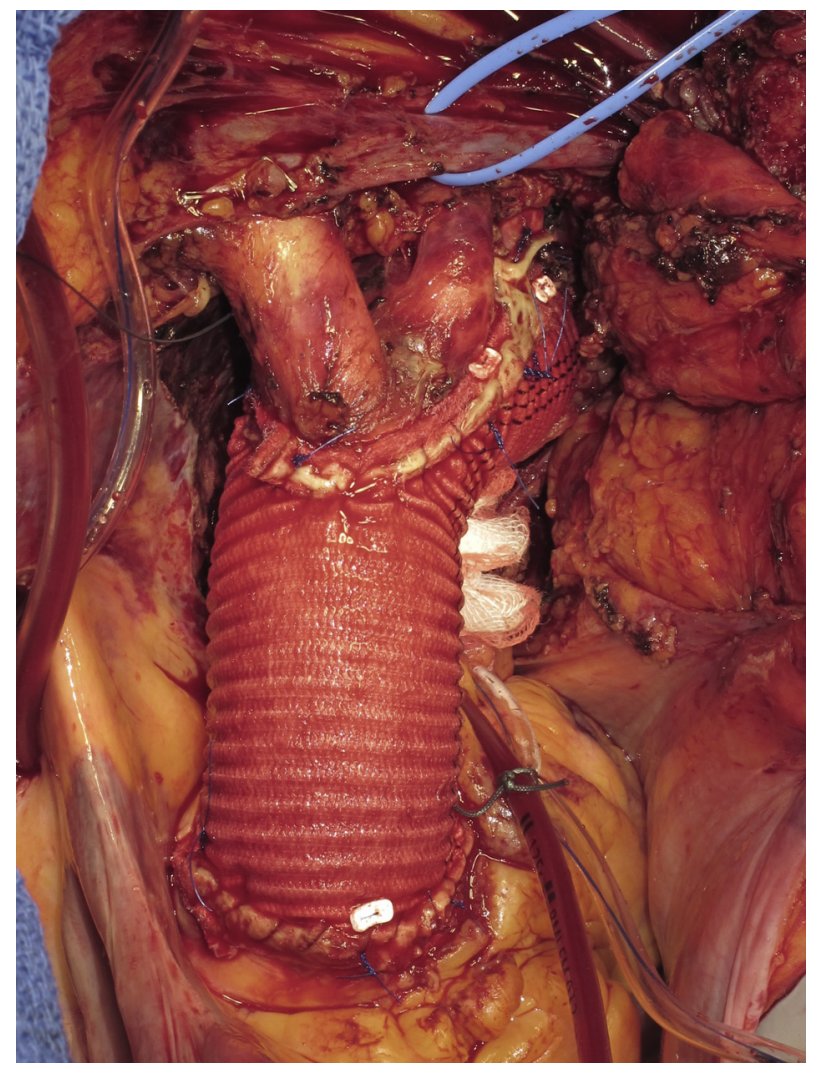

FIGURE 1. Intraoperative situs after repair of the ascending aorta and aortic arch. 


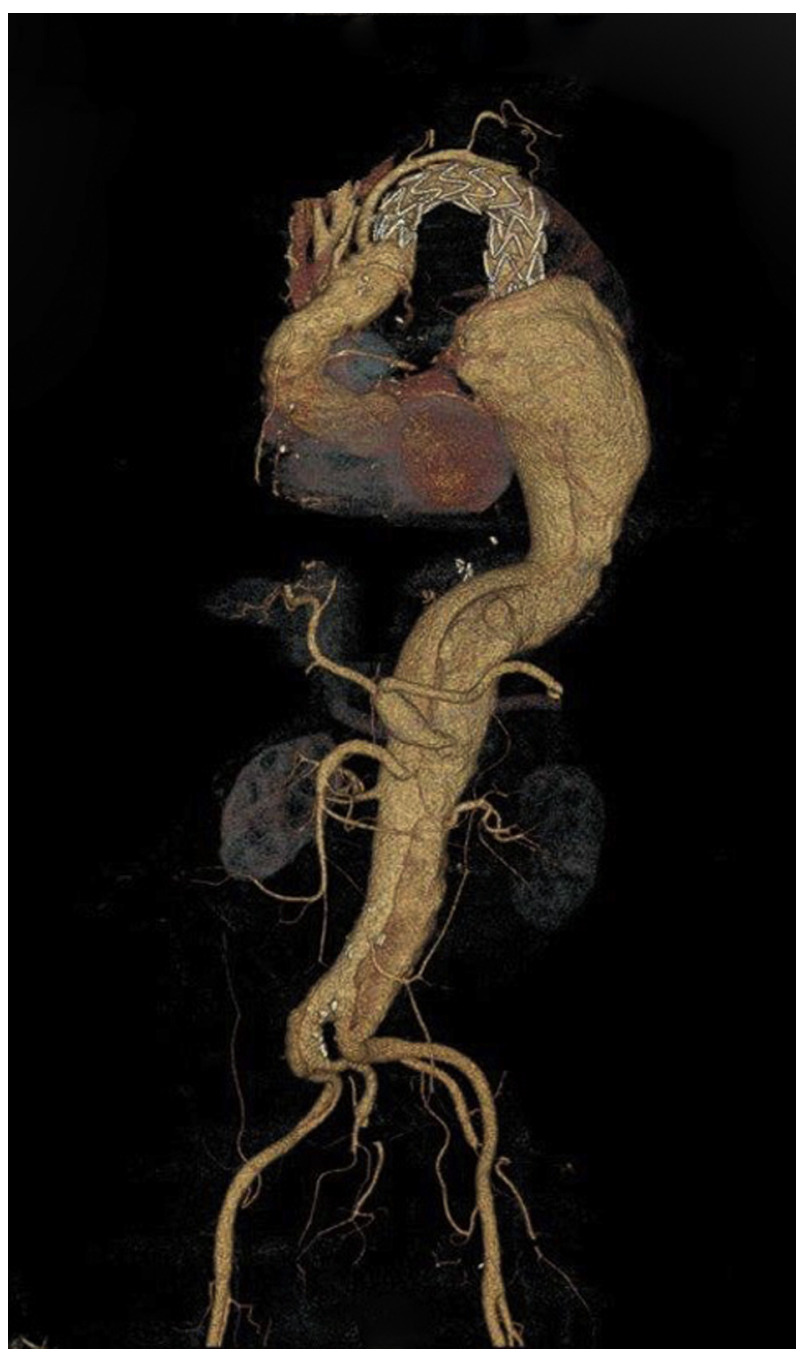

FIGURE 2. Computed tomography scan with 3-dimensional reconstruction in a patient between stage I and II repair, showing the FET and the chronic dissection of the distal aortic segments.

patients $(40.0 \%)$ already had prior thoracic surgery involving repair of the ascending aorta with or without combined valve reconstruction and aortocoronary bypass. Two patients $(13.3 \%)$ had undergone isolated valve reconstruction, and 1 patient $(6.7 \%)$ had undergone aortocoronary bypass. In 3 patients $(20.0 \%)$, an infrarenal repair had been performed. The mean age of patients at the time of operation was 52.9 years (range, 25-78 years), 55.1 years (26-82 years), and 56.6 years (26-82 years) for stages 1 , 2 , and 3, respectively. Demographic data and previous surgical procedures are shown in Table 1.

\section{Technical Data}

Indications for stage 1 repair were aneurysmatic dilatation in 5 patients $(33.3 \%)$, acute aortic dissection in 4 patients $(26.7 \%)$, and aneurysmatic dilatation or newly developed aortic dissection after previous repair in 6

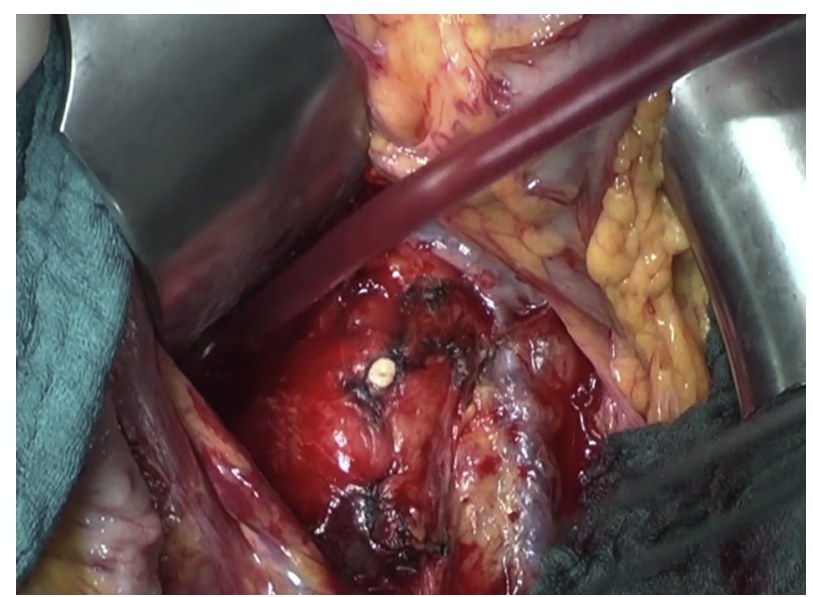

VIDEO 1. Two-vessel debranching (celiac trunk and superior mesenteric artery). Both grafts are tunneled behind the left renal vein, and the graft to the celiac trunk is tunneled in the para-aortal plane. Grafts and anastomoses are intraoperatively controlled using ultrasound. Shown are dissection of the infrarenal aorta, the superior mesenteric artery, and the celiac trunk. Anastomosis of the graft to the native aorta. Anastomosis to the celiac trunk. Anastomosis to the superior mesenteric artery. Video available at: http://www.jtcvsonline.org/article/S0022-5223(17)31357-0/addons.

patients $(40 \%)$. Indications for thoracoabdominal repair were downstream expansion of the aorta due to degenerative aneurysm in 4 patients $(26.7 \%)$ and expansion of the aortic lumen after dissection in 11 patients $(73.3 \%)$. Marfan syndrome was diagnosed in 3 patients $(20 \%)$ with aortic dissection, and Erdheim-Gsell syndrome was diagnosed in 1 patient $(6.7 \%)$. Mean maximal aortic diameter before stage 1 in patients not presenting with acute aortic dissection was $59.5 \mathrm{~mm}$ (range, $48-67 \mathrm{~mm}$ ) and $75 \mathrm{~mm}$ (range, 61-106 $\mathrm{mm}$ ) before stage 2 . All patients presented with aneurysmatic dilation of the aorta involving or reaching beyond the renal arteries. The median interval between stages 1 and 2 was 23.6 months (mean, 23.4 months; range, 1.4-49 months); the interval between stages 2 and 3 was shorter (median, 13 days; mean, 35.7 days; range, $0-187$ days).

Stage 1 could be completed in all patients $(100 \%)$. A total aortic arch repair was performed, as well as repair of the ascending aorta in patients not operated previously. All patients were operated using the FET technique, either using a hybrid graft or deploying a stent graft to stabilize the aortic graft. Cerebral perfusion was maintained via selective unilateral cannulation in 14 patients $(93.3 \%)$ and bilateral cannulation in 1 patient $(6.7 \%)$. Median core temperature was $28^{\circ} \mathrm{C}$ (mean, $28.1^{\circ} \mathrm{C}$; range, $26^{\circ} \mathrm{C}-30^{\circ} \mathrm{C}$ ). Adjunctive procedures were performed, including aortocoronary bypass in 4 patients $(26.7 \%$, redo in 1 case $)$ and aortic valve reconstruction in 6 patients $(40.0 \%)$ (Table 2).

Stage 2 was completed in 14 patients $(93.3 \%)$; 1 patient died after intraoperative rupture of the descending aorta. Infrarenal repair was performed in 9 patients $(60.0 \%)$, using a 


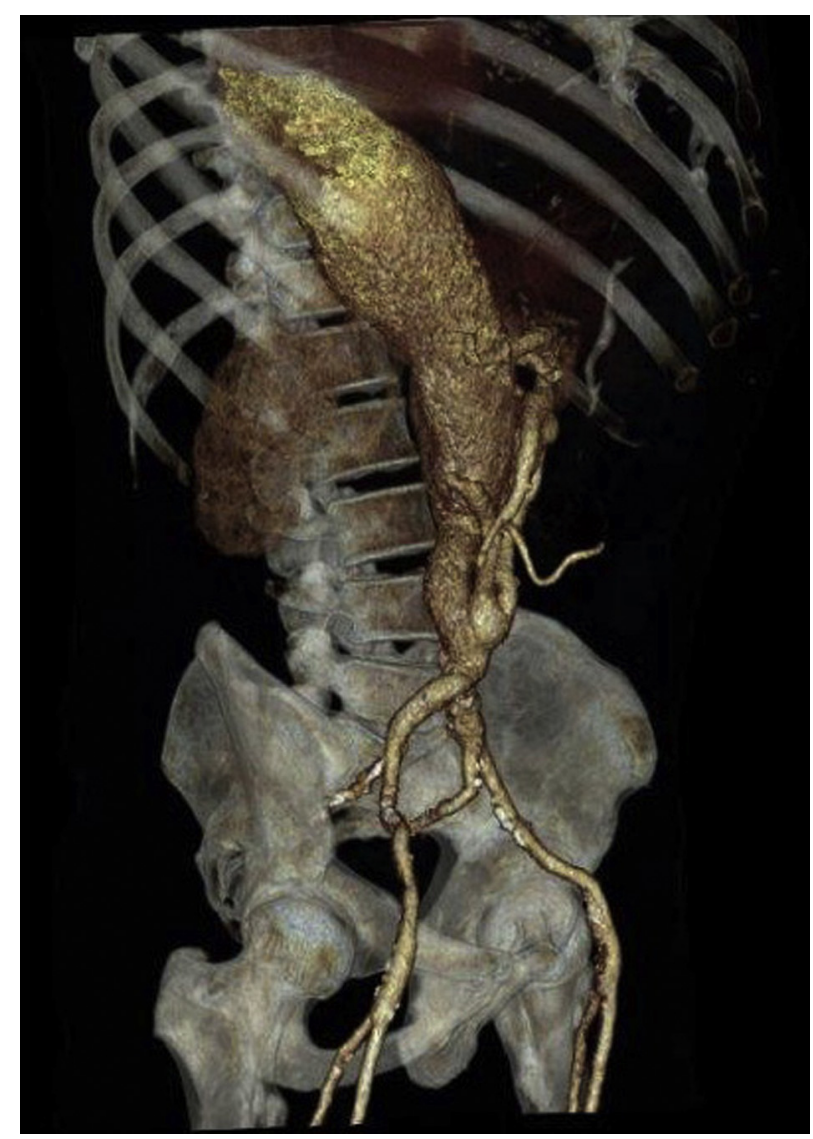

FIGURE 3. Computed tomography scan with 3-dimensional reconstruction in a patient after completion of stage II.

tube $(\mathrm{n}=3,20 \%)$ or bifurcated $(\mathrm{n}=6,40.0 \%)$ graft. In 2 patients $(13.3 \%)$, an already existing aortic graft was replaced to optimize the distal landing zone and to facilitate debranching. Debranching of the superior mesenteric artery was performed in all cases $(\mathrm{n}=15,100 \%)$. The celiac trunk was not revascularized in 2 patients $(13.3 \%)$; in 1 case it was chronically occluded, and in the second case the surgeon deemed the risk for erosion bleeding high due to pancreatitis after infrarenal repair. With the exception of the intraoperative death, all other patients $(93.3 \%)$ received a graft to the right and 13 to the left renal artery $(86.7 \%)$, as in 1 patient an occluded left renal artery was detected preoperatively (Table 2).

Stages 2 and 3 were performed maximally 24 hours apart from each other in the first 3 cases $(20 \%)$, as well as in a patient with contained aortic rupture $(6.7 \%)$. In the latter 11 patients $(73.3 \%)$, we adopted a staged concept for the thoracoabdominal repair with longer intervals, as described earlier. For stage 3, a median of 3 stent grafts (range, 2-5) was necessary to exclude the aneurysm.

\section{Intensive Care and Length of Stay}

Median intensive care unit stay after stage 1 was 1 day (range, 1-45 days), and median invasive ventilation time

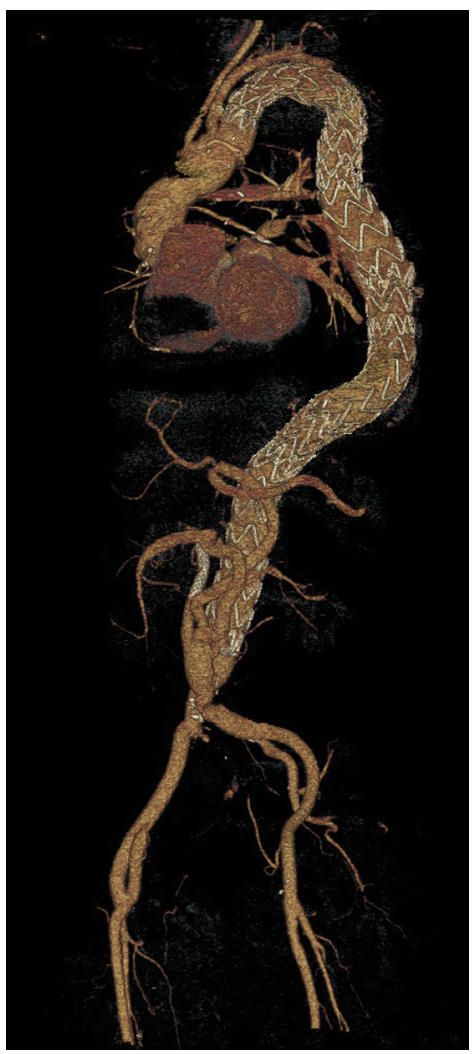

FIGURE 4. Three-dimensional computed tomography reconstruction after completion of the multistaged procedure.

was 0 days (range, 0-32 days). After stage 2, median intensive care unit stay was 5 days (range, 1-30 days) and median ventilation time was 1 day ( $0-20$ days).

\section{Postoperative Outcome and Complications}

One patient $(6.7 \%)$ required temporary dialysis after stage 1 and underwent a right hemicolectomy after caecum perforation. Another patient had to undergo small bowel resection. A rethoracotomy for bleeding was necessary in 2 patients; 1 of those also required a tracheostomy because of prolonged respiratory weaning. One patient required a pacemaker to treat a newly diagnosed atrioventricular block. One patient had a temporary paresis of the recurrent laryngeal nerve. No further neurologic complications were observed. There was no in-hospital mortality after stage 1 .

One patient died intraoperatively during stage 2 after the aneurysm ruptured at the thoracic level. No further postoperative deaths occurred, resulting in an inhospital mortality of $6.7 \%$. One further patient had to undergo a subtotal colectomy, and another patient developed a pancreatitis, which was treated medically. No permanent renal insufficiency was observed after stage 2 .

One patient developed permanent paraplegia $(6.7 \%)$ after undergoing stages 2 and 3 with a short interval period. No further mortality or morbidity was observed after stage 3 . 
TABLE 1. Patients' demographic data and comorbidities (in absolute numbers and relative frequencies, age in years, diameter in $\mathrm{mm}$ with mean and range)

\begin{tabular}{lc}
\hline \multicolumn{1}{c}{ Variable } & $\mathbf{n}(\%)$ \\
\hline Age & \\
Stage I & $52.9(25-78)$ \\
Stage II & $55.1(26-82)$ \\
Stage III & $56.6(26-82)$ \\
Gender & \\
Male & $10(66.7)$ \\
Female & $5(33.3)$ \\
Indication stage I & \\
TAA/TAAA & $5(33.3)$ \\
AAD & $4(26.7)$ \\
Other & $6(40.0)$ \\
Aortic diameter at stage I & \\
Ascending & $59.5(48-67)$ \\
Descending & $51.1(44-63)$ \\
Suprarenal & $43.2(34-61)$ \\
Infrarenal & $34.8(22-57)$ \\
\hline Indication stage II-III & \\
TAAA & $4(26.7)$ \\
CBD & $10(73.3)$ \\
Prior aortic surgery & \\
AAR & \\
With CABG & $5(20.0)$ \\
With AVR & $5(33.3)$ \\
\hline CABG & $2(40.0)$ \\
AVR/MVR & $1(6.7)$ \\
AAA & $4(26.7)$ \\
CAD & $1(6.7)$ \\
Heart failure (NYHA $\geq 2)$ & $2(13.3)$ \\
IDDM & $3(20)$ \\
Liver cirrhosis & $9(60.0)$ \\
\hline Obesity & $5(33.3)$ \\
\hline Previous stroke/TIA & $1(6.7)$ \\
\hline CKD & $1(6.7)$ \\
\hline
\end{tabular}

TAA, Thoracic aortic aneurysm; TAAA, thoracoabdominal aortic aneurysm; $A A D$, acute aortic dissection; $C B D$, chronic B-dissection; $A A R$, ascending aorta repair; $C A B G$, coronary artery bypass grafting; $A V R$, aortic valve reconstruction; $M V R$, mitral valve reconstruction; $A A A$, abdominal aortic aneurysm; $C A D$, coronary artery disease; NYHA, New York Heart Association; IDDM, insulin-dependent diabetes mellitus; TIA, transient ischemic attack; COPD, chronic obstructive pulmonary disease; $C K D$, chronic kidney disease.

We observed 1 aneurysm-related interval complication between stages 2 and 3 in 1 patient presenting with anemia. The computed tomography scan showed a contained rupture and stent graft implantation was carried out immediately.

\section{Follow-up}

Mean follow-up in this cohort was 29 months (range, 1.5-112.4 months). At 3 months, 1 patient showed an endoleak type $\mathrm{Ib}$, which was treated by insertion of an
TABLE 2. Operative technical data (in absolute numbers and relative frequencies, temperature in ${ }^{\circ} \mathrm{C}$, size in $\mathrm{mm}$, time in min with mean and range)

\begin{tabular}{|c|c|}
\hline \multicolumn{2}{|l|}{ Stage I } \\
\hline Technical success & $15(100)$ \\
\hline \multicolumn{2}{|l|}{ Clinical presentation } \\
\hline Emergent/urgent & $6(40.0)$ \\
\hline Elective & $9(60.0)$ \\
\hline Body core temperature (mean, range) & $28.1^{\circ} \mathrm{C}\left(26^{\circ} \mathrm{C}-30^{\circ} \mathrm{C}\right)$ \\
\hline \multicolumn{2}{|l|}{ Aortic graft } \\
\hline $\mathrm{ET}^{*}+$ stent graft $\dagger, \ddagger$ & $3(20.0)$ \\
\hline FET $\S$ & $12(80.0)$ \\
\hline Aortic graft size & $28(24-36)$ \\
\hline \multicolumn{2}{|l|}{ Cerebral perfusion } \\
\hline Unilateral & $14(93.3)$ \\
\hline Bilateral & $1(6.7)$ \\
\hline Circulatory arrest time & $185.1(124-294)$ \\
\hline Clamping time & $122.7(100-177)$ \\
\hline \multicolumn{2}{|l|}{ Adjunctive procedures } \\
\hline CABG & $4(26.7)$ \\
\hline AVR & $6(40.0)$ \\
\hline \multicolumn{2}{|l|}{ Stage II } \\
\hline Technical success & $14(93.3)$ \\
\hline \multicolumn{2}{|l|}{ Clinical presentation } \\
\hline Emergent & $2(13.3)$ \\
\hline Urgent & $4(26.7)$ \\
\hline Elective & $9(60.0)$ \\
\hline \multicolumn{2}{|l|}{ Infrarenal repair } \\
\hline Tube graft & $3(20.0)$ \\
\hline Bifurcation graft & $6(40.0)$ \\
\hline Redo & $2(13.3)$ \\
\hline \multicolumn{2}{|l|}{ Debranching } \\
\hline $\mathrm{TC}$ & $13(86.7)$ \\
\hline SMA & $15(100.0)$ \\
\hline Right RA & $14(93.3)$ \\
\hline Left RA & $13(86.7)$ \\
\hline \multicolumn{2}{|l|}{ Stent graft deployment } \\
\hline Femoral artery & $9(60.0)$ \\
\hline Aortic graft & $5(33.3)$ \\
\hline
\end{tabular}

$\overline{E T \text {, Elephant trunk; } F E T \text {, frozen elephant trunk; } C A B G \text {, coronary artery bypass graft- }}$ ing; $A V R$, aortic valve reconstruction; $T C$, celiac trunk; $S M A$, superior mesenteric artery; $R A$, renal artery. *Intergard Woven vascular graft; Maquet, Rastatt, Germany. $\dagger$ †Relay stent graft system; Bolton Medical, Fla. ‡Valiant and Talent thoracic stent graft systems; Medtronic, Minn. §E-vita open plus hybrid stent graft; Jotec, Hechingen, Germany.

additional stent graft. Four type II endoleaks were detected at 3 months. One resolved spontaneously, and the other 3 persisted without affecting the maximal diameter of the aneurysm and are being monitored.

As expected, this patient cohort showed significant mortality over time (Table 3). All deaths except 1 were not aorta specific. One further patient had a seizure and intra-abdominal bleeding was postulated, although the cause of death remained unclear. Kaplan-Meier analysis showed an overall survival of $93.3 \%, 66.0 \%, 55.0 \%$, and $27.5 \%$ after 1 month and 1,3 , and 5 years, respectively (Figure 5). 
TABLE 3. Causes of early and late mortality

\begin{tabular}{lcl}
\hline Patient & $\begin{array}{c}\text { Time of } \\
\text { death }(\mathbf{m o})\end{array}$ & \multicolumn{1}{c}{ Cause of death } \\
\hline 1 & 1 & Intraoperative aneurysm rupture \\
\hline 2 & 3 & Myocardial infarction \\
\hline 3 & 3 & Cardiac failure with lung edema \\
\hline 4 & 4 & Endocarditis with multiple peripheral emboli \\
\hline 5 & 9 & Grand mal seizure, unclear cause of death \\
\hline 6 & 38 & Myocardial infarction \\
\hline 7 & 46 & Intracranial bleeding \\
\hline 8 & 48 & Ischemic stroke \\
\hline
\end{tabular}

\section{Intention-to-Treat Analysis}

In addition to those patients in whom the multistage procedure was completed, we have performed the first stage in 8 more patients, who presented with aneurysmatic dilation of the distal aorta, nevertheless under the threshold required for a thoracoabdominal repair. Three of those patients required a temporary dialysis after stage 1 ; in 2 further patients, a tracheotomy had to be performed. Prolonged weaning was also observed in 1 patient with pneumonia. One patient underwent rethoracotomy for bleeding. Regarding long-term follow-up, 1 of those patients is lost to follow-up and another had a fatal myocardial infarction 52 days after the first stage, while recovering in a rehabilitation facility. Mean follow-up for this patient cohort is 22.1 months (range, 1-83.2 months).

\section{DISCUSSION}

Endovascular techniques have evolved significantly in the last 2 decades. Being less invasive than open surgery, endovascular therapy options were quickly adopted in many areas of vascular surgery and are today being implemented as supplementary or primary treatment modalities. If applied in combination with open surgery as hybrid procedures, endovascular techniques allow for treatment of pathologies, which would have otherwise required more extensive surgical treatment. We have described a multistage hybrid approach to treat aortic pathologies extending from the aortic root to the distal iliac vessels.

Although some advanced endovascular approaches have been described, ${ }^{7}$ open surgery remains the golden standard for the repair of ascending aorta and the aortic arch. After introduction of the elephant trunk ${ }^{8}$ and the FET, ${ }^{9}$ aortic pathologies reaching up to the proximal descending aorta could be treated in a single operation with relatively low mortality and morbidity. In case of acute aortic dissection, FET induces thrombosis and shrinkage of the false lumen, leading to reverse remodeling, ${ }^{10}$ all of which have been connected to reduced late aortic-related mortality. ${ }^{11,12}$ In patients with chronic dissection reaching distal into the descending and abdominal aorta, such an effect does not

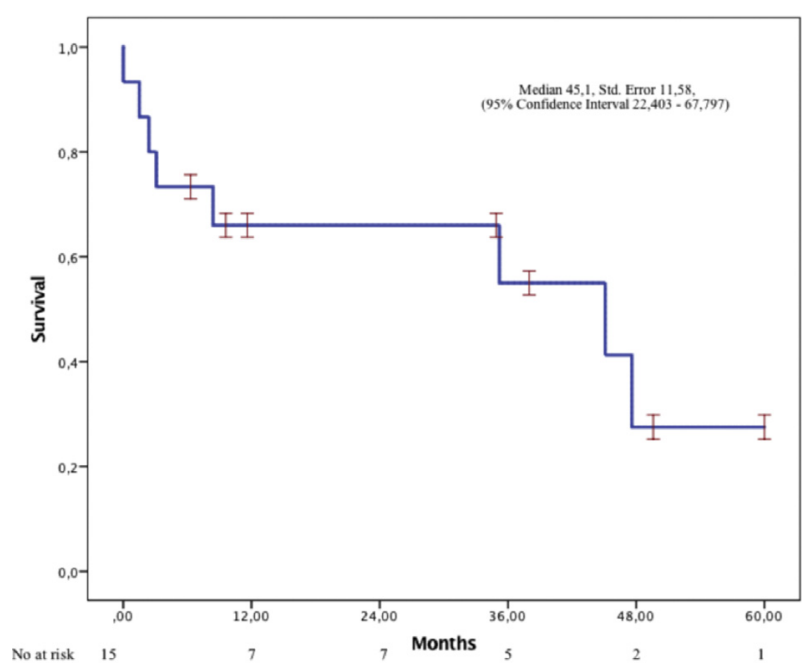

FIGURE 5. Death-free ratio of patients' cohort using the Kaplan-Meier method.

always occur, because perfusion is often maintained through secondary distal intimal tears. However, there is growing evidence that FET reduces late aortic events and secondary interventions in patients with both acute and chronic dissection. ${ }^{13-15}$ Furthermore, even if further interventions are required, FET facilitates thoracoabdominal repair by providing an adequate landing zone for endovascular completion and by distally displacing the aortic anastomosis in case of open repair. The same principle applies to patients with extended aortic aneurysms, where second-stage thoracoabdominal repair is necessary. The postoperative results of FET show an acceptable mortality and morbidity, ${ }^{10,13,16-18}$ considering the fact that many patients present with acute aortic type A dissection. The more "aggressive" repair with FET technique does not lead to a higher operationrelated complication rate in comparison with a more conservative surgical approach. ${ }^{15,19}$ The absence of data showing higher operation-related complications in combination with the lower late aortic-related events seem to justify extending the repair into the descending aorta.

For the thoracoabdominal repair, open surgery still remains the gold standard and shows ongoing good results. $^{20,21}$ Although experience in thoracoabdominal repair is extensive, data regarding this procedure as a component of a multistep aortic repair are limited. In a large series of 133 patients undergoing open distal aortic repair after FET, Roselli and colleagues ${ }^{4}$ reported 37 patients with thoracoabdominal repair. Folkmann and colleagues $^{22}$ also reported a series of 9 patients undergoing open completion. Mortality in both series remained low $(0 \%-6 \%)$, as well as spinal cord injury $(0 \%-3.8 \%)$ and renal insufficiency $(4.9 \%-11 \%)$. Roselli and colleagues ${ }^{4}$ showed that endovascular completion also is a feasible 
option in those patients. A total of 38 patients underwent an endovascular completion with comparable mortality $(6.5 \%)$ and morbidity (4.3\% spinal cord injury and 3.3\% renal insufficiency) to open surgery. As in every other field of vascular surgery, hybrid procedures also have been implemented here. Esposito and colleagues ${ }^{23}$ recently described the Lupiae technique for repair of extensive aortic aneurysms, which consists of debranching of the renovisceral branches using a specially designed graft and covering of the diseased aortic segments by using stent grafts. A total of 35 patients were treated with a mortality of $8.4 \%$. Renal insufficiency requiring dialysis reached $1.7 \%$; no spinal cord injury was reported. ${ }^{23}$

We have adopted a 2-stage concept for the completion of the aortic repair, using a hybrid approach to exclude the distal thoracoabdominal aneurysm. Although the debranching procedure still presents a challenge to the physical limits of patients, it does remain advantageous over open repair by eliminating the need for thoracotomy, high aortic clamping, and extensive dissection of the aorta. Furthermore, hybrid repair is not limited by anatomic limitations, such as access vessel anatomy and atherosclerotic load of target vessels, which may preclude endovascular repair. Chronic dissections present an additional hurdle for endovascular completion, and studies suggest that these pathologies are even more prone to secondary interventions than atherosclerotic aneurysms. ${ }^{24}$ Although midterm results are encouraging and show no differences in reinterventions after endovascular repair in comparison with open surgery, ${ }^{25,26}$ long-term follow-up shows that reinterventions are far more common after complex endovascular procedures and reinterventions become more frequent after approximately 5 years. ${ }^{27,28} \mathrm{We}$ observed clinically relevant endoleaks in 1 patient, which could be treated endovascularly. Type II endoleaks were detected as well, but these did not affect the maximal aneurysm diameter. Some reports have described adverse aortic events attributed to type II endoleaks. ${ }^{29,30}$ Considering the complexity of the disease, as well as the fact that many resolve spontaneously over time, ${ }^{30}$ we have adopted a more "defensive" stance regarding this type of endoleak. Although admittedly endoleaks still remain an issue, we believe that the use of standard stentgrafts in the context of a hybrid procedure results in a robust reconstruction able to offer a durable exclusion of the aneurysm.

Regardless of the type of completion, all series reported no or low spinal cord injury $(0 \%-4.3 \%)$, although definitions vary. In our series as well, only 1 patient had neurologic impairment. Taking under consideration that the extent of repair is a primary risk factor for spinal ischemia, ${ }^{31}$ one would expect the opposite. The low spinal ischemia rate probably has to be attributed to the staged repair, which provides the collateral network with sufficient time to adjust to the perfusion changes. To minimize risk for such complications, when using a bifurcated graft distally to the origin of the hypogastric artery, we always reanastomose this vessel, which has been shown to be a significant supplier of the spinal cord. ${ }^{32}$ Furthermore, the routine use of cerebrospinal fluid drainage in those patients can provide an important tool in counterweighing the effects of spinal cord injury and is advocated by other studies. ${ }^{4,22,23}$

The interval period between stages represents a potential Achilles' heel for this concept. Other authors have reported aneurysm-related interval mortality, which remains significant. ${ }^{4,23,33}$ Furthermore, a significant percentage of patients are not willing to undergo completion of the repair after recovering from the first stage. ${ }^{34,35}$ In our series, 1 patient presented with a contained aortic rupture between stages 2 and 3, and stent graft implantation was performed as an emergency procedure. With growing experience, we have limited waiting time to a period of a few weeks, in which patients are being monitored closely in our outgoing patient clinic.

With the exception of 1 intraoperative death, in-hospital mortality in this patient cohort remained low. In the followup, cause of death was mostly not aneurysm related. Although mortality remains an issue in these complex procedures, Estrera and colleagues ${ }^{33}$ showed that the only independent risk factor for late death after completion was age. Longterm follow-up of patients who did not undergo completion procedures shows an even more increased mortality. ${ }^{33,35}$ In view of these data, we consider the complete aortic repair to be a justified therapeutic option for those patients.

\section{Study Limitations}

This study has several limitations. The cohort consists of a specific group of patients, and this fact should be taken under consideration when making comparisons with alternative treatment options or drawing conclusions. The small number of patients also precludes further subgroup analysis. Although some patients were followed for up to or even more than 5 years, mean follow-up is generally short, thus not allowing for definitive conclusions with regard to durability. Nevertheless, considering the relative lack of bigger cohorts, this article adds valuable knowledge regarding treatment options of extended thoracoabdominal aneurysms.

\section{CONCLUSIONS}

This article shows that the concept of a multistaged hybrid approach is technically feasible in the treatment of extensive aortic disease caused by degenerative aneurysms, as well as after aortic dissection. The FET technique remains a safe treatment approach for stage 1 repair. Staged hybrid repair of the downstream aorta shows encouraging results with low mortality, acceptable morbidity, and promising durability. These are comparable to other treatment 
techniques, although the number of patients included in the existing literature remains low.

\section{Conflict of Interest Statement}

Authors have nothing to disclose with regard to commercial support.

\section{Special acknowledgements to Wojciech Derwich, MD.}

\section{References}

1. Quinones-Baldrich WJ, Panetta TF, Vescera CL, Kashyap VS. Repair of type IV thoracoabdominal aneurysm with a combined endovascular and surgical approach. J Vasc Surg. 1999;30:555-60.

2. O'Callaghan A, Mastracci TM, Eagleton MJ. Staged endovascular repair of thoracoabdominal aortic aneurysms limits incidence and severity of spinal cord ischemia. J Vasc Surg. 2015;61:347-54.e1.

3. Lin PH, Kougias P, Bechara CF, Weakley SM, Bakaeen FG, Lemaire SA, et al. Clinical outcome of staged versus combined treatment approach of hybrid repair of thoracoabdominal aortic aneurysm with visceral vessel debranching and aortic endograft exclusion. Perspect Vasc Surg Endovasc Ther. 2012;24:5-13.

4. Roselli EE, Subramanian S, Sun Z, Idrees J, Nowicki E, Blackstone EH, et al, Endovascular versus open elephant trunk completion for extensive aortic disease, J Thorac Cardiovasc Surg. 2013;146:1408-17.

5. Shrestha M, Bachet J, Bavaria J, Carrel TP, De Paulis R, Di Bartolomeo R, et al. Current status and recommendations for use of the frozen elephant trunk technique: a position paper by the Vascular Domain of EACTS. Eur J Cardiothorac Surg. 2015;47:759-69.

6. Gkremoutis A, Schmandra T, Meyn M, Schmitz-Rixen T, Keese M. Hybrid approach to emergent and urgent treatment of complex thoracoabdominal aortic pathology. Eur J Cardiothorac Surg. 2014;48:407-13.

7. Shah A, Khoynezhad A. Thoracic endovascular repair for acute type A aortic dissection: operative technique. Ann Cardiothorac Surg. 2016;5:389-96.

8. Borst HG, Walterbusch G, Schaps D. Extensive aortic replacement using "elephant trunk" prosthesis. Thorac Cardiovasc Surg. 1983;31:37-40.

9. Kato M, Ohnishi K, Kaneko M, Ueda T, Kishi D, Mizushima T, et al. New graftimplanting method for thoracic aortic aneurysm or dissection with a stented graft. Circulation. 1996;94(9 Suppl):II188-93.

10. Ius F, Fleissner F, Pichlmaier M, Karck M, Martens A, Haverich A, et al. Total aortic arch replacement with the frozen elephant trunk technique: 10-year follow-up single-centre experience. Eur J Cardiothorac Surg. 2013;44:949-57.

11. Fattouch K, Sampognaro R, Navarra E, Caruso M, Pisano C, Coppola G, et al. Long-term results after repair of type a acute aortic dissection according to false lumen patency. Ann Thorac Surg. 2009;88:1244-50.

12. Halstead JC, Meier M, Etz C, Spielvogel D, Bodian C, Wurm M, et al. The fate of the distal aorta after repair of acute type A aortic dissection. J Thorac Cardiovasc Surg. 2007;133:127-35.

13. Pacini D, Tsagakis K, Jakob H, Mestres CA, Armaro A, Weiss G, et al. The frozen elephant trunk for the treatment of chronic dissection of the thoracic aorta: a multicenter experience. Ann Thorac Surg. 2011;92:1663-70.

14. Sun LZ, Qi RD, Chang Q, Zhu JM, Liu YM, Yu CT, et al. Surgery for acute type A dissection using total arch replacement combined with stented elephant trunk implantation: experience with 107 patients. J Thorac Cardiovasc Surg. 2009;138: $1358-62$.

15. Pochettino A, Brinkman WT, Moeller P, Szeto WY, Moser W, Cornelius K, et al. Antegrade thoracic stent grafting during repair of acute DeBakey I dissection prevents development of thoracoabdominal aortic aneurysms. Ann Thorac Surg. 2009:88:482-90.

16. Sun L, Qi R, Zhu J, Liu Y, Zheng J. Total arch replacement combined with stented elephant trunk implantation: a new "standard" therapy for type a dissection involving repair of the aortic arch? Circulation. 2011;123:971-8.

17. Roselli EE. We should replace the aortic arch and more in DeBakey type I dissection A perspective from the Cleveland Clinic. Ann Cardiothorac Surg. 2013;2:216-21.
18. Mestres CA, Tsagakis K, Pacini D, Di Bartolomeo R, Grabenwoger M, Borger M, et al. One-stage repair in complex multisegmental thoracic aneurysmal disease: results of a multicentre study. Eur J Cardiothorac Surg. 2013; 44:e325-31.

19. Easo J, Weigang E, Holzl PP, Horst M, Hoffmann I, Blettner M, et al. Influence of operative strategy for the aortic arch in DeBakey type I aortic dissection: analysis of the German Registry for Acute Aortic Dissection Type A. J Thorac Cardiovasc Surg. 2012;144:617-23.

20. Coselli JS, Bozinovski J, LeMaire SA. Open surgical repair of 2286 thoracoabdominal aortic aneurysms. Ann Thorac Surg. 2007;83:S862-4; discussion S890-2.

21. Murana G, Castrovinci S, Kloppenburg G, Yousif A, Kelder H, Schepens M et al. Open thoracoabdominal aortic aneurysm repair in the modern era: results from a 20-year single-centre experience. Eur J Cardiothorac Surg. 2016;49:1374-81.

22. Folkmann S, Weiss G, Pisarik H, Czerny M, Grabenwoger M. Thoracoabdominal aortic aneurysm repair after frozen elephant trunk procedure. Eur J Cardiothorac Surg. 2015;47:115-9.

23. Esposito G, Pennesi M, Bichi S, Patrini D, Pellegrino P, Redaelli M, et al. Hybric multistep approach to mega-aortic syndrome: the Lupiae technique. Eur J Cardiothorac Surg. 2015;47:126-33.

24. Oikonomou K, Kopp R, Katsargyris A, Pfister K, Verhoeven EL, Kasprzak P. Outcomes of fenestrated/branched endografting in postdissection thoracoabdominal aortic aneurysms. Eur $J$ Vasc Endovasc Surg. 2014;48:641-8.

25. Eagleton MJ, Follansbee M, Wolski K, Mastracci T, Kuramochi Y. Fenestrated and branched endovascular aneurysm repair outcomes for type II and III thoracoabdominal aortic aneurysms. J Vasc Surg. 2016;63:930-42.

26. Ferrer C, Cao P, De Rango P, Tshomba Y, Verzini F, Melissano G, et al. A propensity-matched comparison for endovascular and open repair of thoracoabdominal aortic aneurysms. J Vasc Surg. 2016;63:1201-7.

27. Mastracci TM, Eagleton MJ, Kuramochi Y, Bathurst S, Wolski K. Twelve-yea results of fenestrated endografts for juxtarenal and group IV thoracoabdominal aneurysms. J Vasc Surg. 2015;61:355-64.

28. De Bruin JL, Baas AF, Buth J, Prinssen M, Verhoeven EL, Cuypers PW, et al. Long-term outcome of open or endovascular repair of abdominal aortic aneurysm. N Engl J Med. 2010;362:1881-9.

29. Jones JE, Atkins MD, Brewster DC, Chung TK, Kwolek CJ LaMuraglia GM, et al. Persistent type 2 endoleak after endovascular repair of abdominal aortic aneurysm is associated with adverse late outcomes. J Vasc Surg. 2007;46:1-8.

30. Sidloff DA, Stather PW, Choke E, Bown MJ, Sayers RD. Type II endoleak after endovascular aneurysm repair. Br J Surg. 2013;100:1262-70.

31. Buth J, Harris PL, Hobo R, van Eps R, Cuypers P, Duijm L, et al. Neurologic complications associated with endovascular repair of thoracic aortic pathology: incidence and risk factors. a study from the European Collaborators on Stent/ Graft Techniques for Aortic Aneurysm Repair (EUROSTAR) registry. $J$ Vasc Surg. 2007;46:1103-11.

32. Eagleton MJ, Shah S, Petkosevek D, Mastracci TM, Greenberg RK. Hypogastric and subclavian artery patency affects onset and recovery of spinal cord ischemia associated with aortic endografting. J Vasc Surg. 2014;59: 89-95.

33. Estrera AL, Sandhu HK, Miller CC, Charlton-Ouw K, Nguyen TC, Afifi RO, et al. Repair of extensive aortic aneurysms: a single-center experience using the elephant trunk technique over 20 years. Ann Surg. 2014;260:510-8.

34. LeMaire SA, Carter SA, Coselli JS. The elephant trunk technique for staged repair of complex aneurysms of the entire thoracic aorta. Ann Thorac Surg. 2006;81:1561-9.

35. Etz CD, Plestis KA, Kari FA, Luehr M, Bodian CA, Spielvogel D, et al. Staged repair of thoracic and thoracoabdominal aortic aneurysms using the elephan trunk technique: a consecutive series of 215 first stage and 120 complete repairs. Eur J Cardiothorac Surg. 2008:34:605-15.

Key Words: thoracoabdominal repair, hybrid, mega aortic syndrome, staged 